\title{
Consumer attitude toward using smart shopping carts: a comparative analysis of Italian and Croatian consumer attitudes
}

\author{
Gandolfo Dominici* \\ Department SEAS, \\ Università di Palermo, \\ Viale delle Scienze ed. 13, \\ 90128 Palermo, Italy \\ and \\ Business Systems Laboratory, \\ viale Fr. Scaduto $2 /$, \\ 90144, Palermo, Italy \\ Email: gandolfo.dominici@libero.it \\ *Corresponding author
}

\section{Matea Matić}

Department of Management, University of Dubrovnik, Lapadska obala 7, 20000 Dubrovnik, Croatia

Email: matea.matic@unidu.hr

\section{Tindara Abbate and Davide Di Fatta}

Department of Economics, Università di Messina,

Via dei Verdi, 75 - 98122, Messina, Italy

Email: abbatet@unime.it

Email: difatta.davide@gmail.com

\begin{abstract}
This paper aims to explore consumer attitudes toward using smart shopping cart, considering country of origin, gender, age, and intentions to use smart shopping carts while purchasing. Moreover, it investigates the influence of extracted factors on consumers' attitudes toward using smart shopping carts and the users' levels of digital competence. The data was collected through survey questionnaires using a purposive sample of 313 Croatian and Italian respondents. To this end, we applied statistical methodologies such as binary logistic regression, factor analysis, and analysis of variance. We found that, compared with Croatians, Italian respondents have a more positive attitude toward using smart shopping carts, regardless of age or gender. Moreover, we found that consumers are influenced by two major factors: functional and convenience. Consumers who purchase for functionality reasons will have preferences associated with faster product selection and speeding up the purchasing process without fearing that they lack the necessary expertise. If functionality has the tendency to increase, respondents will not lack ICT knowledge when purchasing with the smart cart.
\end{abstract}


Keywords: internet retailing; smart shopping cart; functional factors; convenient factors; Croatia.

Reference to this paper should be made as follows: Dominici, G., Matić, M., Abbate, T. and Di Fatta, D. (2016) 'Consumer attitude toward using smart shopping carts: a comparative analysis of Italian and Croatian consumer attitudes', Int. J. Electronic Marketing and Retailing, Vol. 7, No. 3, pp.229-244.

Biographical notes: Gandolfo Dominici is an Associate Professor of Marketing in the Department SEAS at the Polytechnic School, University of Palermo, Italy. He is co-Founder and Scientific Director of the Business Systems Laboratory. He is member of the Board of Directors of the World Organisation for Systems and Cybernetics (WOSC) and a board member of the Italian Universities Consortium of Industrial Economics and Management (CUEIM) and of the International Society for the Systems Sciences (ISSS). He is the Editor-in-Chief of the International Journal of Electronic Marketing and Retailing, International Journal of Digital Culture and Tourism and International Journal of Markets and Business Systems and the editorial board member of a number of international journals. His main research topics are marketing and systems thinking.

Tindara Abbate is Assistant Professor of Business Economics and Management at the University of Messina (Italy). She received her Master of Science in Planning and Control from Scuola Aforisma of Lecce, and her PhD in Business Economics and Management of the University of Messina (Italy). She has been involved, as presenter, in several national and international conferences. She has been involved in research projects, as member and scientific coordinator. Her research interests refer to market orientation; open innovation; destination marketing.

Matea Matic is an Assistant Professor at the Department of Economics and Business Economics, University of Dubrovnik. She participated in several national and international research projects as a researcher, expert. Her work was published in some of the world's leading journals as well as all major Croatian journals in the field of economics. Her fields of interest are consumer behaviour, strategy marketing, online marketing, online environment, online consumer behaviour and online strategy marketing.

Davide Di Fatta is a PhD student in Economics and Management at the University of Messina (Italy). He collaborates with the SEAS Department at the Polytechnic School of the University of Palermo (Italy). He is a junior member referent of the Business System Laboratory. His main research fields are systems thinking, digital marketing and social media marketing.

\section{Introduction}

Interest in smart shopping carts is growing for consumers and retailers. The idea is basically to equip the cart with scanners that track the total cost of the consumer's shopping basket when they are inside the store (Manchanda et al., 1999). 
The main advantage, in addition to enabling shoppers to track their in-store spending, is the improvement in customer satisfaction obtained by offering customised and timely promotions, recommending complementary products, sharing nutritional information, and recipes (Hui et al., 2013). Moreover, smart carts and other similar technologies can attenuate the complexity of the shopping experience (Palumbo and Dominici, 2014).

From the retailers' point of view, it is important to note the behaviour of budget shoppers: the results on the effect of real-time spending feedback are perceived as an unexpected gain (Levav and McGraw, 2009). Budget shoppers spend their entire budget to maximise their utility (Du and Kamakura, 2008). Therefore, budget shoppers who receive real-time spending feedback spend it readily and more frivolously.

Otherwise, non-budget shoppers reduce their spending by replacing national brands with lower-priced store brands, while budget shoppers increase the total amount of money they spend by purchasing a greater number of national brands. Therefore, while budget shoppers purchase national brands additively, non-budget shoppers purchase store brands substitutively (Van Ittersum et al., 2013).

The use of store brands and of promotions, particularly out-of-store promotions, is associated with different psychographic factors. Store-brand use correlates mainly with traits related to economic benefits and costs, whereas the use of out-of-store promotions is associated mainly with traits related to hedonic benefits and costs (Ailawadi et al., 2001). These differences result in four well-defined and identifiable consumer segments: deal-focused consumers, store-brand-focused consumers, deal and store brand users (who use all), and non-users of either store brands or deals (who use none).

A burgeoning literature focuses on the subject of 'in-store decision making': according to Inman et al. (2009), category characteristics such as purchase frequency displays, as well as customer characteristics, such as household size and gender, all affect in-store decision.

Moreover, although the author's analysis reveals that the baseline probability of an unplanned purchase is $46 \%$, contextual factors can drive this as high as $93 \%$ (Inman et al., 2009). For this reason, 'real-time feedback spending' (Voss et al., 2003; Welch et al., 2005) should be also considered.

Although there is an extensive body of literature on these aspects (Mano and Oliver, 1993; Planning, 1996; Bakewell and Mitchell, 2003; Green Atkins and Kim, 2012), most of the discussions have focused on smart shopping - defined as the tendency for consumers to invest considerable time and effort in seeking and utilising promotion-related information to achieve price savings (Mano and Elliot, 1997).

There has been little analysis of consumer attitudes toward using smart shopping carts, and only a few contributions have focused on factors that may have some influence on their use: for instance, the role of gender in technology adoption has been studied (Gefen and Straub, 1997); similarly, some scholars (Chen, 1986; Shashaani, 1993;) believe that males have better computational abilities than females. Other scholars have noted in their studies that gender plays no significant role in technology adoption. From a general point of view, the role of gender in technology adoption has received some attention (Zmud, 1979); however, there is a paucity of literature on the influence of gender on attitudes toward using smart shopping carts: therefore, there is a need to learn more about the factors that influence their use.

The present study aims to explore the key factors that determine the use of smart shopping carts, with a specific focus on country of origin (Warren, 2015), gender, age 
and the intentions to use a smart shopping cart while purchasing. It also intends to analyse the influence of extracted factors, the tendency to use (measure for attitude), and concerns about levels of ICT knowledge.

With this in mind, we put forward the two research questions:

RQ1 What are the key factors that determining the use of smart shopping carts?

RQ2 What are the relationships among these factors?

We carried out a survey questionnaire using a purposive sample of 313 Croatian and Italian respondents. Statistical analyses, including binary logistical regression, factor analysis, and analysis of variance (ANOVA), were used. The results of the regression indicate that respondents who have a positive attitude toward using smart shopping carts will probably be more inclined to using the smart carts while purchasing in the future, and are more likely to be Italian, regardless of age or gender. Two further factors were also extracted using factor analysis: Factor 1 is related to the functionality and efficiency features of the respondents and has been named the functional factor, whilst factor 2 is related to the convenience and simplicity features and is referred to as the convenient factor. The results of the ANOVA show that there is a significant difference between the functionality factor and a lack of ICT knowledge, as well as attitude toward using smart shopping carts. For the second factor, the results show that there is a significant difference between the convenience factor and the attitude toward using the smart shopping cart. Additionally, the results indicate that there is no significant difference between convenience and lack of ICT knowledge.

The paper is structured as follows. The following section provides a literature review. The third section then describes the research methodology and Section 4 presents and discusses the findings. The final section then contains our conclusions, highlighting the implications for scholars and practitioners, as well as the limitations and indications for further research.

\section{Literature review}

Many research studies in the literature show that low-income households not only spend a large share of their income on food, but also exhibit a higher income elasticity of demand for food than does the rest of the population (Hymans and Shapiro, 1976).

Considering the theoretical division between 'budget' and 'non-budget' shoppers, we can see that budget shoppers tend to minimise the risk of overspending; because they are uncertain about how much of their budget they have already spent, they are inclined to spend significantly less than their budget constraints. Kahneman et al. (1991) suggested that the negative consequences associated with overspending and underspending are asymmetric - in other words, overspending is viewed as a loss, while opportunity costs are viewed as foregone gains.

Because losses are weighted more heavily than foregone gains, budget shoppers likely are more concerned about overspending than under-spending. Thus, budget shoppers build a safety margin in order to minimise the likelihood of spending more than their budget. This margin can be viewed as a monetary measure of an implicit and figurative cost: the cost of bearing the risk of exceeding their budget (Arrow, 1971). 
Real-time spending feedback (i.e., through smart shopping cart systems) may thus improve the consumer welfare of budget shoppers by reducing their spending uncertainty, thus enabling them to spend more of their budget without the risk of exceeding it. For these reasons, scholars have focused on the study of purchasing behaviour subject to budget constraints. Existing theories suggest that real-time spending feedback allows budget shoppers to increase their utility, given their budget constraints (Lynch and Ariely, 2000).

The resulting improvement in shopping experience, as well as the increase in spending, will benefit not only the buyer but also the retailer. Therefore, smart shopping carts may be an interesting win-win strategy both for shoppers and for retailers (Van Ittersum et al., 2010).

Other scholars (Dhar and Wertenbroch, 2000; Shiv and Fedorikhin, 2000; Briers and Laporte, 2013) have contributed to the growing body of research on in-store decision making. The salience of hedonic dimensions is greater when consumers decide which of several items to give up (forfeiture choices) than when they decide which item to acquire (acquisition choices): a hedonic item is relatively preferred over the same utilitarian item in forfeiture choices than in acquisition ones.

What are practical implications of this? Gaining a better understanding of smart shopping, first of all, will enable retailers to better segment consumers. Furthermore, retailers could also provide a combination of utilitarian and hedonic experiences for consumers, in order to maximise their satisfaction and consumption. Arnold and Reynolds (2003) developed a six-factor scale that consists of adventure, gratification, role, value, social, and idea shopping motivations. Using such six-factors hedonic shopping motivation profiles, their findings reveal five shopper segments: the Minimalists, the Gatherers, the Providers, the Enthusiasts, and the Traditionalists.

Shopping momentum occurs when an initial purchase provides a psychological impulse that enhances the purchase of a second, unrelated product (Dhar et al., 2007). The most promising theoretical mechanism for shopping momentum comes from Gollwitzer's (1990) theory of implementation and deliberation mind-sets. ${ }^{1}$

Instead, other researchers have suggested that a hedonic driver item is more likely to reinforce a deliberative mind-set: temptations tend to activate higher priority goals spontaneously (Fishbach et al., 2003). Thus, a hedonic or frivolous purchase may spontaneously bring to mind the importance of being frugal as a means of effective self-regulation.

Bénabou and Tirole (2004) developed a theory of internal commitments or 'personal rules' based on self-reputation over one's willpower, which transforms lapses into precedents that undermine future self-restraint.

The foundation for this mechanism is the imperfect recall of past motives and feelings, leading people to draw inferences from their past actions. The degree of self-control an individual can achieve is shown to increase with his or her self-confidence and to decrease with prior external constraints.

Among these factors, Warren (2015) focuses on the country-of-origin effect. In third section, our analysis will take into account not only the country of origin (Italy and Croatia in our sample), but will also consider gender, age, and the intention to use smart shopping carts while purchasing.

Other scholars have studied the role of gender in technology adoption (Gefen and Straub, 1997): Chen (1986) and Shashaani (1993) believed that males have better 
computational abilities than females; however, our research noted that gender plays no significant role in technology adoption.

\section{Data and methodology}

The data was collected through a survey questionnaire using a purposive sample of 313 consumers from Dubrovnik-Neretva County, Croatia and 100 consumers from Palermo, Italy. The empirical study was carried out in May and June 2015. The questions were based on the review of literature and a two-part questionnaire was developed as a result. The first part included statements on a five-point Likert scale, where respondents were asked to express the degree of their agreement (1: strongly disagree; 5 : strongly agree) relating to the features of smart shopping cart, and their tendency to use a smart shopping cart ("If I have the possibility, I would always use a smart shopping cart") and one statement ("Using the shopping cart is:") with dichotomous (Bad/Good) answers. The second part of questionnaire included the demographic variables of the respondents (gender, age, and country of origin).

Table 1 Sample statistics

\begin{tabular}{|c|c|c|c|}
\hline \multirow[t]{2}{*}{ Country variable } & \multirow[t]{2}{*}{ Categories } & $\begin{array}{c}\text { Croatia } \\
(N=213)\end{array}$ & $\begin{array}{c}\text { Italy } \\
(N=100)\end{array}$ \\
\hline & & Percentage (\%) & Percentage (\%) \\
\hline \multirow[t]{2}{*}{ Gender } & Male & 39 & 59.0 \\
\hline & Female & 61 & 41.0 \\
\hline \multirow[t]{4}{*}{ Age } & $18-20$ & 15.5 & 2.0 \\
\hline & $21-25$ & 40.4 & 5.0 \\
\hline & $26-30$ & 29.1 & 83.0 \\
\hline & $31-35$ & 15.0 & 10.0 \\
\hline \multirow{2}{*}{$\begin{array}{l}\text { Using a shopping } \\
\text { cart is: }\end{array}$} & $\mathrm{Bad}$ & 7.5 & 1.0 \\
\hline & Good & 88.3 & 99.0 \\
\hline \multirow{5}{*}{$\begin{array}{l}\text { If I have the } \\
\text { possibility, I would } \\
\text { always use a smart } \\
\text { shopping cart }\end{array}$} & Strongly disagree & 5.2 & 3.0 \\
\hline & Disagree & 8.5 & 10.0 \\
\hline & Neither disagree nor agree & 29.1 & 36.0 \\
\hline & Agree & 27.2 & 28.0 \\
\hline & Strongly agree & 30.0 & 23.0 \\
\hline \multirow{5}{*}{$\begin{array}{l}\text { I am worried that } \\
\text { purchasing with a } \\
\text { smart shopping cart } \\
\text { will show my lack of } \\
\text { ICT knowledge }\end{array}$} & Strongly disagree & 51.6 & 4.0 \\
\hline & Disagree & 18.3 & 14.0 \\
\hline & Neither disagree nor agree & 18.3 & 38.0 \\
\hline & Agree & 5.2 & 31.0 \\
\hline & Strongly agree & 6.6 & 13.0 \\
\hline
\end{tabular}

Note: Research findings ( $\mathrm{N}=313)$.

The results obtained from the survey were analysed using different analytical tools, including methods of analysis and synthesis, inductive and deductive methods, method of generalisation and specialisation, and different statistical methods, including binary 
logistic regression analysis. Linear regression estimates the coefficients of the linear equation, involving one or more independent variables that best predict the value of the dependent variable. Table 1 presents the characteristics of the analysed sample.

As shown in Table 1, the sample consists of 313 respondents, with 213 respondents from Dubrovnik-Neretva County in Croatia; of these, 39\% are male and $61 \%$ are female, mostly between 21 to 25 years old. The remaining 100 respondents are from Palermo in Italy, of which $59 \%$ are male and $41 \%$ are female, mostly between 26 to 30 years old. For the Croatian sample, the results show that most of the respondents would like to use smart carts in shopping, and also that they are not worried about their lack of ICT knowledge in using the smart shopping carts. Also, similar results for the Italian sample indicate that most of the respondents would like to use smart carts during shopping, and also that they are not worried about their lack of ICT knowledge in using the smart shopping carts. The Croatian respondents expressed slightly higher negative attitudes toward using a smart shopping cart than did the Italian respondents.

Theoretical models and empirical evidence suggest that the attitude toward using smart shopping carts may be determined by a set of factors, such as county of origin, age, and intention to use smart shopping carts. In order to explore which factors influence the attitude toward smart shopping carts, binary logistic regression should be performed. Binary logistic regression is similar to linear regression, except that it is used when the dependent variable is nominal; it assumes that the dependent variable is dichotomous and that the outcomes are independent and mutually exclusive - that is, that a single case can only be represented once and must be in one group or the other (Tabachnick and Fidell, 2007). The model can be expressed as follows.

$$
\begin{aligned}
\ln \left(\frac{A(\text { attitude })}{1-A(\text { attitude })}\right)= & \beta_{0}+\beta_{1} \cdot \text { country_of_origin } \\
& +\beta_{2} \cdot \text { age }+\beta_{3} \text { intention_smart_shopping_card }
\end{aligned}
$$

The dependent variable is the odds ratio, where $A($ attitude) is the predicted probability of the event which coded with 1 (in this case, of a positive attitude toward smart shopping carts) and the X's are the predictor variables: the country of origin, age, and intention to use smart shopping carts (the categories of these variables are given in Table 1). The binary logistic regression and factor analysis are performed using SPSS 20.0 software and ANOVA.

\section{Results and discussion}

The model diagnostics and the results of the model testing by binary logistic regression analysis are presented in Table 2. The first part of Table 2 shows the model diagnostics and the second part shows the coefficients and odds ratios of the regression equation. Table 2 summarises the overall number and percentages of the predicted variable data points for the two categories of the predicted variable. The overall percentage shows the percent of cases for which the dependent variables was correctly predicted, given the model. In classification table of this analysis, the overall percentage of $95.4 \%$ shows that in $95.4 \%$ of cases, attitude (bad/good) is correctly predicted by the model. The sensitivity and specificity of the test show that $41.2 \%$ of occurrences are correctly predicted, as are $98.6 \%$ of the non-occurrences. 
The Hosmer-Lemeshow tests the null hypothesis that the data fit the model well - that is, that there is a linear relationship between the predictor variables and the log odds of the criterion variable. Comparing the observed frequencies with those expected under the linear model, a chi-square statistic is computed. A non-significant chi-square indicates that the null hypothesis is accepted and that the data fit the model well. In this case, the data fit the model well, since the significance of Hosmer-Lemeshow test is greater larger than 0.05 (sig. $=0.283$ ).

Table 2 Model diagnostics and results of estimation

\begin{tabular}{|c|c|c|c|}
\hline \multicolumn{4}{|c|}{ Model diagnostics } \\
\hline \multicolumn{4}{|l|}{ Classification table results } \\
\hline Overall percentage correct & & & 95.4 \\
\hline Sensitivity & & & 41.2 \\
\hline Specificity & & & 98.6 \\
\hline \multicolumn{4}{|c|}{ The cut-off value is 0.500} \\
\hline \multicolumn{4}{|l|}{ Hosmer-Lemeshow test } \\
\hline Chi-square & & & 9.466 \\
\hline Sig. & & & .305 \\
\hline \multicolumn{4}{|c|}{ Results of estimation } \\
\hline & Coefficient $\beta$ & Odds ratio & Sig. \\
\hline Country of origin & 2.471 & & \\
\hline Age & -.054 & & \\
\hline Gender & .670 & & \\
\hline Intention to use shopping carts & & & .000 \\
\hline \multicolumn{4}{|l|}{ Strongly disagree (RC) } \\
\hline Disagree & 1.891 & 6.626 & .029 \\
\hline Neither disagree nor agree & 3.380 & 29.359 & .000 \\
\hline Agree & 3.724 & 41.444 & .000 \\
\hline Strongly agree & 4.520 & 91.812 & .000 \\
\hline Constant & -.628 & .534 & .554 \\
\hline
\end{tabular}

Notes: Research findings $(\mathrm{N}=313)$. RC: Reference category.

Predictors that met the conventional 0.05 standard for statistical significance (Table 2) are interpreted as follows:

- The odds ratio of 11.831 for Country of origin means that there is a higher probability that Italian respondents have a have positive attitude toward using shopping carts than do the Croatian respondents

- The odds ratios for all categories of Intention to use shopping carts mean that there is a higher probability of a positive attitude in the case of those respondents who disagree, neither disagree nor agree, agree, and strongly agree with the statement "If I have the possibility, I would always use smart shopping cart" than in the case of those who strongly disagree with given statement. 
As shown in Table 2, two of the variables in the model (country of origin and intention to use shopping carts) have a statistically significant impact on the probability of the intention to use smart shopping carts. This does not hold true for the age variable.

Considering the fact that the intention to use smart carts is coded on five-point Likert scale, it is evident from the coefficients (Table 2) that, with higher intention to use smart shopping carts, the probability of intention to use smart shopping carts increases. Also, consumers who are more inclined to use the smart carts while purchasing are more likely to be Italian respondents, regardless of their age. As shown in Table 2, there is an 11.831 times greater probability of Italian respondents using smart shopping cart than of Croatian respondents using them.

These findings are in accordance with previous researches by Warren (2015), who studied the relationship between the country of origin effect and shopping patterns, the response to advertising mediums, and layout demographics.

Respondents who agree that they have a positive attitude toward using smart shopping carts have a 41.444 times greater probability of using smart carts while shopping than those who strongly disagree with the statement "If I have the possibility, I would always use a smart shopping cart". Those respondents who strongly agree with this statement have a 91.812 times greater probability of using the smart cart while shopping than those who strongly disagree with it. As the results of the study show, if consumers have stronger positive attitudes toward using smart carts, they will also be more inclined to use the smart shopping cart while purchasing.

These consumers will probably be more open towards ICT innovation and, therefore, will more likely be interested in using smart shopping carts during shopping. They also are more likely to have higher awareness of the benefits of using smart carts, due to their convenience and functionality features. Also, using smart shopping carts will probably save them time and effort, as well as provide flexibility in payment and delivery terms, etc. It can be concluded that consumers with a positive attitude toward smart shopping carts will probably be more inclined to use smart shopping cart, and will use them to achieve a higher-quality shopping experience. It can also be concluded that the findings of the regression analysis are consistent with the literature background (Bénabou and Tirole, 2004).

The results of the regression analysis for variable ages show that there is no statistically significant difference between the age of respondents and their attitude to using smart carts while purchasing. These results are consistent with the research of Dean (2008): the correlation between age and perceived service complexity was not found to be significant.

In further analysis, we performed factor analysis on the measurement scale features of the smart shopping cart. Explorative factor analysis shows that, out of the total 14 statements, four had low loading (less than 0.4). These statements were therefore excluded from further analysis, in order to achieve a better one-dimensional, reliable, convergent, and discriminant validity of the measurement scale. As an initial step in multivariate statistical approach, it is necessary to determine the internal reliability of the measurement scale features of the smart shopping cart. To determine the internal consistency from the diagnostics of analysis, Cronbach's alpha coefficient was used. Table 3 shows the Cronbach's alpha coefficient for the measurement scale features of the smart shopping cart. 
Table 3 Reliability of measurement scale features of the smart shopping cart

\begin{tabular}{lc}
\hline Number of variable & Cronbach's alpha \\
\hline 11 & .848 \\
\hline
\end{tabular}

Note: Research findings $(\mathrm{N}=313)$.

These results show a high value of Cronbach's alpha coefficient $(0.845)$, indicating the high reliability of the measurement scale features of the smart shopping cart. The construct of the convergent and discriminant validity of the measurement scale is examined through confirmatory factor analysis.

Table 4 Kaiser-Meyer-Olkin test and Bartlett's test of sphericity measurement scale features of the smart shopping cart

\begin{tabular}{lc}
\hline Kaiser-Meyer-Olkin test & .869 \\
Bartlett's test of sphericity $\chi^{2}$ chi-square & $1,021.573$ \\
Degree of freedom df & 55 \\
Significance & .000 \\
\hline
\end{tabular}

Note: Research findings $(\mathrm{N}=313)$

Table 4 shows the results of the KMO test and the Bartlett test of sphericity. The result of the Kaiser-Meyer-Olkin test is very high $(\mathrm{KMO}=0.869)$ and the Bartlett test of sphericity is statistically significant $(\alpha \leq 0.05)$. Hence, the adequacy of the sample is established and the scale is unidimensional. Further, principle component factor analysis with the varimax rotation method and the Kaiser-Guttman criterion is performed on the data. According to the Kaiser-Guttman criterion, the model may include only those factors with eigenvalues above 1. Consequently, two components or variables with eigenvalues above 1 are extracted (Table 5).

Table 5 Total variance explained for measurement scale features of smart shopping cart

\begin{tabular}{|c|c|c|c|c|c|c|}
\hline \multirow[b]{2}{*}{ Items } & \multicolumn{3}{|c|}{ Initial eigenvalues } & \multicolumn{3}{|c|}{ Rotation sums of squared loadings } \\
\hline & Total & $\begin{array}{c}\text { Variance } \\
\%\end{array}$ & $\begin{array}{c}\text { Cumulative } \\
\%\end{array}$ & Total & $\begin{array}{c}\text { Variance } \\
\%\end{array}$ & $\begin{array}{c}\text { Cumulative } \\
\%\end{array}$ \\
\hline 1 & 4.39 & 39.89 & 39.89 & 3.18 & 28.95 & 28.95 \\
\hline 2 & 1.42 & 12.96 & 52.85 & 2.63 & 23.87 & 52.85 \\
\hline
\end{tabular}

Notes: Extraction method: Principal component analysis.

Research findings $(\mathrm{N}=313)$

Based on the results, it can be seen that $28.95 \%$ of the total variance is explained by Factor 1 and $23.87 \%$ by factor 2 . Together, these variables explain more than $50 \%$ of the total variance. Figure 1 shows the values of the factors by scree test for the measurement scale features of the smart shopping cart. 
Figure 1 Scree test of measurement scale features of smart shopping cart

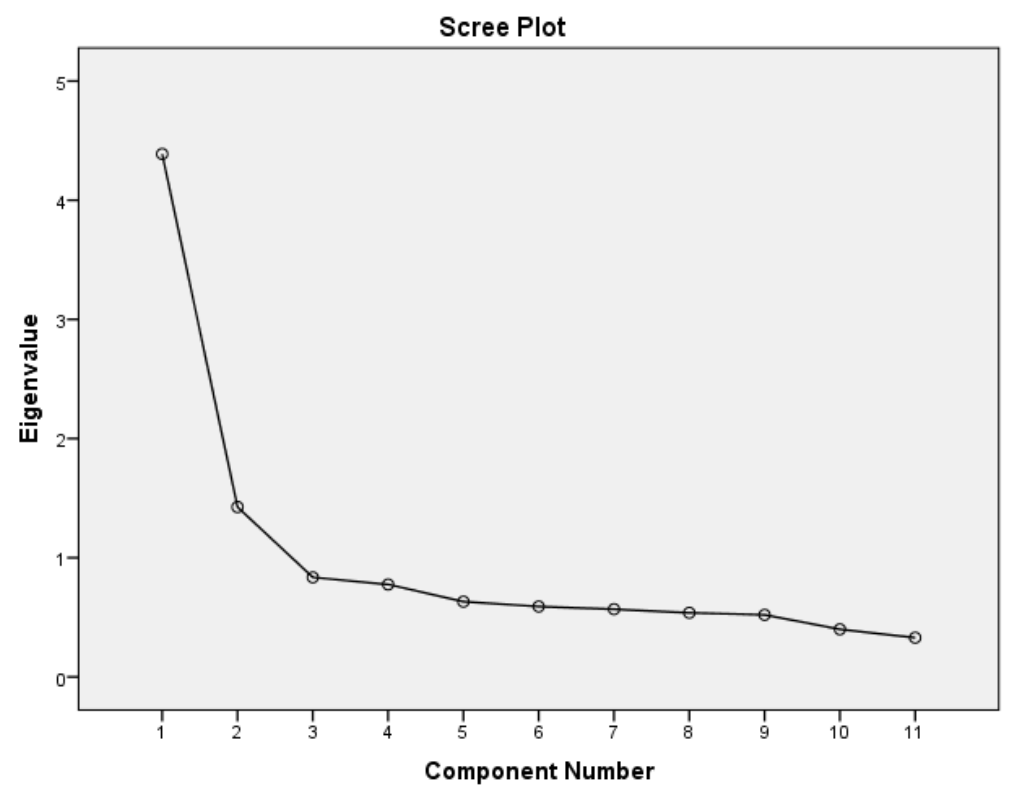

Note: Research findings $(\mathrm{N}=313)$.

The rotated component matrix and the extracted reduction were obtained in further analysis. The matrix of rotated factor structure achieves the goal of data reduction (on factor 2) and is the best summary of the linear relations. The lateral dimensions of the involvement of the sample have almost perfect form, with all the manifested variables showing significant loading $(>0.4)$, which suggests excellent properties of convergent and discriminant validity. The results of the factor analysis for the scale features of the smart shopping cart therefore indicate excellent properties of convergent and discriminant validity. As per the content of the statements, it can be concluded that Factor 1 is related to the functionality and efficiency features of the respondents; it is therefore referred to as the functional factor. Factor 2 is related to convenience and simplicity features, and is thus named the convenience factor.

Further ANOVA was performed to determine the relation between the factors and gender, lack of ICT knowledge, and attitude toward using smart shopping carts. Table 6 shows the results of ANOVA, and it can be seen that there is a significant difference between factor and gender, lack of ICT knowledge, and attitude toward using smart shopping carts.

Table 6 ANOVA between the functional factor and lack of ICT knowledge and attitude toward using smart shopping cart

\begin{tabular}{lccccc}
\hline & $\begin{array}{c}\text { Sum of } \\
\text { squares }\end{array}$ & $d f$ & $\begin{array}{c}\text { Mean } \\
\text { square }\end{array}$ & $F$ & Sig. \\
\hline Lack of ICT knowledge & 37.482 & 4 & 9.370 & 10.565 & .000 \\
Attitude toward using smart shopping cart & 8.731 & 1 & 8.731 & 8.942 & .003 \\
\hline
\end{tabular}

Note: Research findings $(\mathrm{N}=313)$. 
The results also indicate that there are significant differences between the functionality and lack of ICT knowledge $(\mathrm{p}<0.000, \mathrm{~F}=10.565)$.

Table 7 shows the results of the ANOVA between the functional factor and lack of ICT knowledge and attitude toward using smart shopping carts. Therefore, if functionality has the tendency to increase, the respondents will not feel they lack ICT knowledge when using the smart carts. These consumers are open to new technologies and innovation, making the process of purchasing desirable and simple. Additionally, the results suggest that those consumers who purchase due to functionality features will have preferences associated with faster product selection and expediting purchase process without fear that they lack technical knowledge.

The results of the ANOVA indicate that there are significant differences between the functional factor and the attitude toward using smart shopping carts $(p<0.003$, $\mathrm{F}=8.942$ ). These results indicate that, if functionality increases, then consumers will be more inclined to use smart shopping carts while purchasing. Such shopping environments fulfil the requirements of consumers and provide them with the information they need to know immediately, such as instant price checks, availability of products, and so on. These features will also provide consumers with useful information about products, in order to give them the most efficient purchase experience. In this context, the existing functionality while shopping will satisfy consumer preferences and introduce a wide range of useful information in order to achieve hyperconsumption by consumers. Table 7 shows the results of ANOVA between the convenience factor and lack of ICT knowledge and attitude toward using smart shopping carts.

Table 7 ANOVA between the convenience factor and lack of ICT knowledge and attitude toward using smart shopping carts

\begin{tabular}{lccccc}
\hline & $\begin{array}{c}\text { Sum of } \\
\text { squares }\end{array}$ & $d f$ & $\begin{array}{c}\text { Mean } \\
\text { square }\end{array}$ & $F$ & Sig. \\
\hline Lack of ICT knowledge & 6.251 & 4 & 1.563 & 1.575 & .181 \\
Attitude toward using smart shopping carts & 20.586 & 1 & 20.586 & 21.653 & .000 \\
\hline
\end{tabular}

Note: Research findings $(\mathrm{N}=313)$.

Unlike the results for the functional factor, the results for the convenience factor indicate that the lack of ICT knowledge has no statistically significant influence on the convenience motive $(\mathrm{p}<0.181, \mathrm{~F}=1.575)$. On the other hand, the results reveal that there is a significant difference between the convenience factor and the attitude toward using smart shopping carts. These results indicate that consumers who purchase only for convenience features will have a stronger tendency to purchase using the smart shopping cart, mostly likely because it will save them time and effort. This purchase method enables them to achieve their desired level of comfort, especially in the terms of payment and delivery systems. All the convenient features of smart shopping carts - such as advanced delivery and payment systems, comprehensive shopping list, and consumer information from loyalty programs - influence consumers' positive attitude, as they consider this form of purchase to be customised to them. It can be concluded that, at present, consumers who are more inclined to convenient purchasing will probably have a higher positive tendency to use smart shopping carts, as they consider this type of purchase serviceable and supportive. 


\section{Conclusions}

A device as trivial as a shopping cart may contribute to shaping exchanges in supermarkets, because it can completely modify consumers' calculations. It does so by leading them to accomplish particular gestures, by transforming a budgetary constraint into a volumetric one, and by providing them with true calculative tools (Cochoy, 2008).

Based on a sample of 313 Croatian and Italian consumers, this paper explores attitudes toward using smart shopping carts, taking into consideration country of origin, gender, age, and intention to use smart shopping carts during shopping. The regression results indicate that respondents who have positive attitudes toward using smart shopping carts will probably be more inclined to use a smart cart when shopping in future, and are likely to be Italian, regardless age or gender. Country of origin is thus demonstrated to be a significant factor for making purchases with smart shopping carts, thus reflecting the preferences of convenience-oriented Italian consumers (Liefeld, 2004). Additionally, if the consumers have stronger positive attitudes toward using smart carts, they will also be more inclined to use smart shopping carts while shipping in future. These consumers will probably be more open to ICT innovation and will therefore be more likely interested in using smart shopping carts when making a purchase. They also probably have higher awareness of the positive impact of using smart carts, due to their convenience and functional motives. In terms of practical implications from the customer point of view, the probability of a positive attitude toward smart shopping carts increases with stronger intention to use smart shopping carts: in other words, consumers will have a higher tendency to use smart carts while purchasing, as they will consider this form of shopping to be easy to use and useful. Research results show that age and gender do not influence consumer attitude toward using smart shopping carts.

Furthermore, our findings for the factor analysis indicate that consumers are influenced by two major factors - the namely functional and convenience factors. The results of the ANOVA show that there is a significant difference between the functional factor and lack of ICT knowledge. If functionality has the tendency to increase, respondents will not feel that they lack ICT knowledge when shopping with the smart cart. Additionally, the results suggest that the consumers who purchase for functionality reasons will have preferences associated with faster product selection and speeding up the purchase process without fear of lacking expertise. Also, the results indicate that there is a significant difference between the functional factor and attitude to using smart shopping carts.

Such shopping environments fulfil the requirements of consumers and provide them with the information they really want to know, such as instant price checks, availability of products, and so on. Based on the research results, others practical implications emerge: the functionality of smart shopping carts will positively influence consumer perceptions, because they consider this process of purchasing to be more convenient than traditional forms of purchase.

From the retailers' point of view, gaining a better understanding of smart shopping will enable a better process for segmenting consumers: retailers could also provide a combination of utilitarian and hedonic experiences for consumers, in order to maximise their satisfaction and consumption (Arnold and Reynolds 2003). 
Further research could also show an interest in online shopping carts: Close and Kukar-Kinney (2010) investigate consumers' motivations for placing items in an online shopping cart with or without buying - termed 'virtual cart use'. While retailers offer virtual carts as functional holding spaces for intended online purchases, their study reveals other powerful utilitarian and hedonic motivations that explain the frequency of consumer' online cart use, such as securing online price promotions, obtaining more information on certain products, organising items, and entertainment. It has been observed that impulse buying and price dependency are increasing among mobile shoppers in the smart phone age (Park et al., 2015).

For what concerns our results for the convenience factor, our findings indicate that a lack of ICT knowledge has no statistically significant influence on overall consumer satisfaction with the purchasing experience. On the contrary, the results of the ANOVA indicate that there is a significant difference between the functional factor and the attitude toward using smart shopping cart. It can be concluded that, these days, consumers who are more inclined to convenience purchases will probably have higher positive tendency to use smart shopping carts, as they consider this type of purchase to be helpful and valuable.

Consumers who will use smart shopping carts because of the convenience they offers will do so as they are open to new technologies and embrace its benefits. Also, for functional factor, consumers will have positive tendency toward using smart shopping carts, as they consider this to be practical and conducive for purchase.

\section{Managerial implications}

From retailers' point of view, our results show that the customisation of the purchasing process is undoubtedly required, and is essential for making the web-purchasing experience better and easier (Sia et al., 2009). Making the purchasing experience attractive and enjoyable for consumers has the potential to increase their consumption and retention rates. We found different attitudes towards smart shopping carts in Italy and Croatia, which implies that online retailers should use different approaches in these two countries, given the different attitude of consumers towards this shopping tool.

\section{Research limitations and further research}

The main limitation of this study is that it was conducted on a limited sample in only two countries. This, of course, limits the generalisation of the results. Moreover, it could be useful to note some limitations about the selected sampling method: purposive samples can be prone to researcher bias. Therefore, future research could expand the sample to give greater strength to the analysis or to use probability sampling in order to produce better estimates of population totals.

To better analyse the significance of the country of origin factor for making purchases with smart shopping carts, further studies must be conducted by replicating the survey in a larger number of countries. 


\section{References}

Ailawadi, K.L., Neslin, S.A. and Gedenk, K. (2001) 'Pursuing the value-conscious consumer: store brands versus national brand promotions', Journal of Marketing, Vol. 65, No. 1, pp.71-89.

Arnold, M.J. and Reynolds, K.E. (2003) 'Hedonic shopping motivations', Journal of Retailing, Vol. 79, No. 2, pp.77-95.

Arrow, K.J. (1971) Essays in the Theory of Risk Bearing, Markham Publishing Co., Chicago.

Bakewell, C. and Mitchell, V.W. (2003) 'Generation Y female consumer decision-making styles', International Journal of Retail and Distribution Management, Vol. 31, No. 2, pp.95-106.

Bénabou, R. and Tirole, J. (2004) 'Willpower and personal rules', Journal of Political Economy, Vol. 112, No. 4, pp.848-86.

Briers, B. and Laporte, S. (2013) 'A wallet full of calories: the effect of financial dissatisfaction on the desire for food energy', Journal of Marketing Research, Vol. 50, No. 6, pp.767-781.

Chen, M. (1986) 'Gender \& computers', Journal of Educational Computing Research, Vol. 16, No. 2, pp.50-55.

Close, A.G. and Kukar-Kinney, M. (2010) 'Beyond buying: motivations behind consumers online shopping cart use', Journal of Business Research, Vol. 63, No. 9, pp.986-992.

Cochoy, F. (2008) 'Calculation, qualculation, calqulation: shopping cart arithmetic, equipped cognition and the clustered consumer', Marketing Theory, Vol. 8, No. 1, pp.15-44.

Dean, D.H. (2008) 'Shopper age and the use of self-service technologies', Managing Service Quality: An International Journal, Vol. 18, No. 3, pp.225-238.

Dhar, R. and Wertenbroch, K. (2000) 'Consumer choice between hedonic and utilitarian goods', Journal of Marketing Research, February, Vol. 37, No. 1, pp.60-71.

Dhar, R., Huber, J. and Khan, U. (2007) 'The shopping momentum effect', Journal of Marketing Research, August, Vol. 44, No. 3, pp.370-378.

Du, R.Y. and Kamakura, W.A. (2008) 'Where did all that money go? Understanding how consumers allocate their consumption budget', Journal of Marketing, November, Vol. 72, No. 6, pp.109-131.

Fishbach, A., Ronald, S. Friedman, R.S. and Kruglanski, A.W. (2003) 'Leading us not into temptation: momentary allurements elicit overriding goal activation', Journal of Personality and Social Psychology, February, Vol. 84, No. 2, pp.296-309.

Gefen, D. and Straub, D.W. (1997) 'Gender differences in the perception \& use of e-mail: an extension to the technology acceptance model', MIS Quarterly, Vol. 21, No. 4, pp.340-389.

Gollwitzer, P.M. (1990) 'From weighing to willing: approaching a change decision through pre- or post-decisional implementation', Organizational Behavior and Human Decision Processes, February, Vol. 45, No. 1, pp.41-46.

Green Atkins, K. and Kim, Y.K. (2012) 'Smart shopping: conceptualization and measurement', International Journal of Retail and Distribution Management, Vol. 40, No. 5, pp.360-375.

Hui, S.K., Inman, J.J., Huang, Y. and Suher, J. (2013) 'The effect of in-store travel distance on unplanned spending: applications to mobile promotion strategies', Journal of Marketing, March, Vol. 77, No. 2, pp.1-16.

Hymans, S.H. and Shapiro, H.T. (1976) 'The allocation of household income to food consumption', Journal of Econometrics, Vol. 4, No. 2, pp.167-188.

Inman, J.J., Winer, R.S. and Ferraro, R. (2009) 'The interplay among category characteristics, customer characteristics, and customer activities on in-store decision making', Journal of Marketing, Vol. 73, No. 5, pp.19-29.

Kahneman, D., Knetsch, J.L. and Thaler, R.H. (1991) 'The endowment effect, loss aversion, and status quo bias', Journal of Economic Perspectives, Vol. 5, No. 1, pp.193-206.

Levav, J. and McGraw, A.P. (2009) 'Emotional accounting: how feelings about money influence consumer choice', Journal of Marketing Research, February, Vol. 46, No. 1, pp.66-80. 
Liefeld, J.P. (2004) 'Consumer knowledge and use of country of origin information at the point of purchase', Journal of Consumer Behaviour, Vol. 4, No. 2, pp.85-87.

Lynch, J.G. and Ariely, D. (2000) 'Wine online: search costs affect: competition on price, quality, and distribution', Marketing Science, Vol. 19, No. 1, pp.83-103.

Manchanda, P., Ansari, A. and Gupta, S. (1999) 'The 'shopping basket': a model for multi-category purchase incidence decisions', Marketing Science, Vol. 18, No. 2, pp.95-114.

Mano, H. and Elliott, M.T. (1997) 'Smart shopping: the origins and consequences of price savings', Advances in Consumer Research, Vol. 24, No. 1, pp.504-510.

Mano, H. and Oliver, R.L. (1993) 'Assessing the dimensionality and structure of the consumption experience: evaluation, feeling, and satisfaction', Journal of Consumer Research, December, Vol. 20, No. 3, pp.451-466.

Palumbo, F. and Dominici, G. (2014) 'Unraveling the complexity of tourist experience with NFC technology and mobile wallets', in Erçetin, S.S. and Banerjee, S. (Eds.): Chaos, Complexity and Leadership 2013, pp.189-196, Springer.

Park, C., Jun, J.K. and Lee, T.M. (2015) 'Do mobile shoppers feel smart in the smartphone age?', International Journal of Mobile Communications, Vol. 13, No. 2, pp.157-171.

Planning, G.S. (1996) ‘Smart shopping', Marketing Journal, Vol. 1, No. 96, pp.10-12.

Shashaani, L. (1993) 'Gender differences in computer experience and its influence on computer attitudes', Journal of Educational Computing Research, Vol. 11, No. 4, pp.347-367.

Shiv, B. and Fedorikhin, A. (2000) 'Heart and mind in conflict: the interplay of affect and cognition in consumer decision making', Journal of Consumer Research, Vol. 26, No. 3, pp.278-292.

Sia, C.L., Lim, K.H., Leung, K., Lee, M.K., Huang, W.W. and Benbasat, I. (2009) 'Web strategies to promote internet shopping: is cultural-customization needed?', MIS Quarterly, Vol. 33, No. 3, pp.491-512.

Tabachnick, B.G. and Fidell, L.S. (2007) Using Multivariate Statistics, 5th ed., Pearson Education, Inc., Boston.

Van Ittersum, K., Pennings, J.M.E. and Wansink, B. (2010) 'Trying harder and doing worse: how grocery shoppers track in-store spending', Journal of Marketing, Vol. 74, No. 2, pp.90-104.

Van Ittersum, K., Wansink, B., Pennings, J.M.E. and Sheehan, D. (2013) 'Smart shopping carts: how real-time feedback influences spending', Journal of Marketing, Vol. 77, No. 6, pp.21-36.

Voss, K.E., Spangenberg, E.R. and Grohmann, B. (2003) 'Measuring the hedonic and utilitarian dimensions of consumer attitude', Journal of Marketing Research, Vol. 40, No. 3, pp.310-320.

Warren, H.B. (2015) 'Smart shopping and the African American consumer', Proceedings of the 1998 Multicultural Marketing Conference, pp.179-182.

Welch, G.F., Howard, D.M., Himonides, E. and Brereton, J. (2005) 'Real-time feedback in the singing studio: an innovatory action-research project using new voice technology', Music Education Research, Vol. 7, No. 2, pp.225-249.

Zmud, R.W. (1979) 'Individual differences and MIS success: a review of the empirical literature', Management Science, Vol. 25, No. 10, pp.966-979.

\section{Notes}

1 In this theory, shopping momentum occurs because the initial purchase moves the consumer from a deliberative to an implemental mind-set, thus driving subsequent purchases (Gollwitzer, 1990). 